\title{
The Rhetorical Power of a Compelling Story: A Critique of a "Toughlove" Parental Support Group
}

\section{Thomas A. Hollihan and Patricia Riley}

\begin{abstract}
"Toughlove" is a network of parental support groups designed to aid families with delinquent children. The program urges parents to use strict discipline to control their children's behavior and denies that parents are to blame for the failings of their offspring. Using the perspectives suggested by dramatism and Walter R. Fisher's "narrative paradigm," this study critiques the Toughlove story and assesses the rhetorial impact of storytelling in a Toughlove group. While the "Toughlove" rhetoric is found to be highly compelling to the parents in need, it is also found to be quite risky.
\end{abstract}

KEY CONCEPTS Toughlove, narrative, storytelling, support groups, parenting, families, delinquency, problem-children.

Thomas A. Hollihan (Ph.D., The University of Nebraska, 1978) is Associate Professor in the Department of Communications Arts and Sciences, The University of Southern California, Los Angeles, CA 90089-1694. Patricia Riley (Ph.D., The University of Nebraska, 1982) is Assistant Professor in the Department of Communications Arts and Sciences, The University of Southern California, Los Angeles, CA 90089-1694. The authors would like to thank Walter R. Fisher and James F. Klumpp for their very helpful comments on this paper.

It has recently been said that almost the bitterest and most hopeless tragedies of all are the tragedies of parents with bad children. The tragedy of children with bad parents is no less acute.... R. Cowell, Cicero and the Roman Republic, 1967, p.298.

amilies through the ages have been troubled by misbehaving and, at times, delinquent children. In 49 B.C., Cicero blamed his brother for his nephew Quintus' treacheries saying: "His father has always spoilt him but his indulgence is not responsible for his being untruthful or grasping or wanting in affection for his family, through it perhaps does make him headstrong and self-willed as well as aggressive" (Cicero, Cited in Cowell, 1967 , p. 299). Twenty centuries later, contemporary researchers, practitioners, and theorists continue to investigate the exceedingly complex interaction of parental actions, societal and cultural pressures, genetic predispositions, and children's behavioral choices that too often culminate in disaster or despair. Such studies still reflect Cicero's penchant for locating blame for juvenile delinquency in parental actions: e.g., parents who drink too much (Morehouse and Richards, 1982); parental realtionships characterized by a 
great deal of conflict (Emery, 1982); parents who are lax in discipline (Fischer, 1983); abusive parents (Paperny and Deisher, 1983); or parents who fail to provide good nutritious food for their children (Stasiak, 1982).

Rather than suffer the disparagement of neighbors and relatives, or the accusations of teachers and counseling professionals, many parents try to cope with their problem children alone (Nemy, 1982). Recently, a program called "Toughlove" has begun to provide parents of delinquent children with emotional support and hope for solutions to their common problems. "Toughlove" proselytizes that it is not the parents who are failing, it is their children. Founded by Phyllis and David York, the Toughlove groups promote highly disciplined child rearing practices in an attempt to stop unruly teenagers from controlling households, to rid parents of guilt feelings, and to enable parents and non-problem children to lead a normal family life (Nemy, 1982).

The Toughlove approach has attracted a great deal of national attention. It was endorsed by Ann Landers (1981), reported in Time ("Getting Tough," 1981), People ("David and Phyllis," 1981), Ms. (Wohl, 1985), and the New York Times (Nemy, 1982), and was featured on the "Phil Donohue Show" and ABC's "20-20." Partially as a result of this publicity, there are currently more than four-hundred Toughlove groups in the United States and Canada (Nemy, 1982).

A recent Gallup Poll reported that 37 percent of the respondents felt that the main problem with parents today was they they did not give their children sufficient discipline (cited in Wohl, 1985). The increased popularity of the Toughlove program has undoubtedly been a response to these sentiments. Toughlove has been credited with having sparked a series of books advising parents on how to discipline their children (Wohl, 1985; Bodenhamer, 1984; Sanderson, 1983; and, Bartocci, 1984).

Toughlove, like Alcoholics Anonymous, operates primarily through a system of self-help groups that attempt to better peoples' lives, help them cope with crises, and teach them their own limitations (Alibrandi, 1982; Pattison, 1982; and Pomerleau, 1982). A rhetorical study of Toughlove should give insight into the appeal of this group and into the process that similar self-help groups use to become support systems. More importantly, the study of Toughlove will permit researchers to focus on how members are acculturated into the Toughlove philosophy, and how this philosophy guides their lives.

This study involved the observation of a series of Toughlove group meetings and an analysis of the flow of messages during these meetings. The form of these messages can best be described as the telling of individual stories, and ultimately the development a shared group story. The study is grounded in the notion that these shared stories give insight into the group members' beliefs, actions, and worldviews, and into the process through which they attempt to change their lives. This perspective is best explicated in Walter R. Fisher's (1984) notion of the "narrative paradigm."

In developing the "narrative paradigm," Fisher (1984) asserted that 
human beings were essentially storytelling creatures and that the dominant mode of human decision making involved the sharing of these stories. Such stories contained "good reasons" which provided insight into the proper courses of human action. According to this perspective, the world consists of a set of stories from which people must choose. People are thus constantly engaged in storytelling and in evaluating the stories they are told (Fisher, 1984, pp. 7-8).

Where the rational world paradigm would expect individuals (advocates) to possess knowledge of subject matter and of the requirements of argumentative form-thereby creating experts with a capability for argument beyond that possessed by naive advocates - the narrative paradigm presumes that all persons have the capacity to be rational. Rationality is thus a function of the "narrative probability" and "narrative fidelity" of a given story - the degree to which stories hang together, their ability to make sense of encountered experience, and whether they corroborate previously accepted stories (Fisher, 1984).

Shared stories play an important role in the lives of those who tell them, for they are a way for people to capture and relate their experiences in the world. These stories respond to people's sense of reason and emotion, to their intellects and imagination, to the facts as they perceive them, and to their values. People search for stories which justify their efforts and resolve the tensions and problems in their lives, and desire stories that resolve their dissonance and are psychologically satisfying.

Those who do not share in the storytelling-those whose life experiences demand different types of stories-might view particular stories as mere rationalization, but this is to miss the very nature of the storytelling process. In this framework, one person's life story is another's rationalization, but if a story serves a useful purpose to those who tell it or listen to it, that story likely will be retold in the generative process of narrative understanding.

This study has three major goals: (1) to operationalize Fisher's narrative paradigm through actual observations; (2) to identify the Toughlove story; and, (3) to critique the appeal of that story and discuss its possible consequences.

\section{Method}

A Toughlove group in a Los Angeles suburb was observed during four consecutive, three hour meetings. Two researchers attended the meetings and took extensive notes, each attempting to copy down as many of the participant's comments as possible in order to capture the essense of the discussion. We were not allowed to tape record the sessions because the group leaders feared that the presence of taping equipment might "chill" the participants and prevent them from talking in detail about their problems.

The group leaders (two women who founded the group after experiencing difficulties with their own children) were briefed about the nature of the study prior to the first observation. One of the leaders introduced us before our first 
meeting with the group and asked if anyone objected to our presence. No one objected. We explained to the group that we were interested in watching real-life groups as a part of a small group research project underway at a local university. After each meeting, the Touhglove group leaders were asked if the group's participants had behaved differently due to our presence. On each occasion, the leaders indicated that there appeared to be no differences in the group members' interactions. After the last observation we conducted interviews with several randomly selected group members. Each interviewee was asked, if they felt the obeservation affected the group in any way. Again, no differences were reported.

Following the final observation, each observers' notes were prepared for analysis. While it would have been preferable to have access to complete transcripts of the group meetings, we discovered that our written notes were quite detailed and provided us with a great deal of rhetoric for analysis. We proceeded by first, comparing our notes and eliminating issues of disagreement, and second, sub-dividing the information into actual remarks made by group members and our own comments about the group's process. We next sub-divided the group members' statements into three categories that emerged from the notes: (1)story-lines ("Story-lines have beginnings, middles, and ends which give individual actions meanings, provide unity and selfdefinition to individual lives..." (Frentz, 1985, p. 5)); (2) questions or comments to other parents, and (3) procedural issues (mainly leader comments).

Our approach is similar to a "mini-ethonography" where the observers are also the message analysists (Knapp, 1979). This perspective ensures that the highly emotional tone of the meeting, together with the dramatic nature of narrative fiction, are captured in the analysis. After the study was completed, the group as a whole was debriefed.

\section{The Group}

The group had been in existence for just over one year when the observations took place. While the group had a nucleus of eight parents who always attended the meetings, the group's size increased significantly during the observation period. Twelve persons attended the first observed meeting, but by the fourth meeting there were more than thirty parents. The growing attendance may have resulted from a story on the group which appeared in a local newspaper. Following the last observed meeting the group split into two smaller groups in order to maintain the close personal atmosphere necessary for the highly emotional, self-disclosive discussions. All of the participating parents had experienced, or were in the midst of experiencing, a family crisis precipitated by their child's (or children's) behavior.

Parents came from a variety of occupational and socio-cultural backgrounds, but they were predominantly from middle-class, blue collar families. They were also primarily Caucasian (one Hispanic couple attended, but no Blacks or Asians). Several couples attended, but most of the members were 
women. Many were single parents-mothers and fathers-and the vast majority of the women worked outside of the home.

The problems faced by these parents were generally quite serious, including simple acts of rebellion, physical assaults, and threats of murder. The most common problems were drug and alcohol abuse. To illustrate the kinds of behavioral problems discussed by the group, a description of some of the children follows (all names are fictitious):

Ellen-A 13 year old female who skips school, steals from her parents, and during the time of the observation had run away from home.

Bill-A 15 year old male who struck his father's head against the headboard of his bed while he was asleep.

Mark-An 18 year old male who had been arrested for theft, breaking and entering, assault, and selling drugs. At the time of the observations, he was serving a one year sentence in a juvenile correction facility.

Angie-A 15 year old female who carried a knife, had physical altercations with her mother, threatened her father by describing a dream in which she murders him, and was involved in a youth gang.

John-A 16 year old male who had beaten his mother with a baseball bat, assaulted her with a knife, and painted "fuck the fat ugly bitch" on their living room wall.

Maria-A 12 year old female who had run away from home and who was, during the time of observation, a prostitute.

Keith-A 24 year old male who had no job, refused to leave home, and who threatened to beat his mother because she refused to allow him to smoke marijuana in their living room.

Analysis of the parents' stories showed drug or alcohol abuse to be present in slightly more than two-thirds of the cases. The remainder of the cases seemed to reflect either problems of general disobedience or psychological/emotional disturbances. It was not uncommon for parents to come to group meetings with blackened eyes or other visible bruises from violent confrontations with their children. Many parents reported that they were terrified of their own children and, in several cases, parents claimed that their children had threatened them with violence merely because they planned to attend the Toughlove meeting.

\section{The Sharing of the Toughlove Story}

In each meeting, individual tales of fear and helplessness were transformed into hope and perseverance as these stories were woven into shared narrative fiction. If parents truly loved their children, they could not let them destroy themselves or their families; they had to be tough-this was the Toughlove story.

The meetings can best be described as extended storytelling sessions where the members, together, created a powerful, compelling, and cohesive story. Numerous sagas of their children's triumphs over drugs or alcohol were 
often repeated as part of the "ritual" acculturation of the new members. This was far more than imparting information to the newcomers; the retelling was always a highly emotional experience for the parents, often tearful at the start, ending in the quiet determination that they had regained control over their lives. Through the storytelling, the parents transformed their lives into a moral drama, suffused with righteousness, that absolved them of their guilt and restored orderliness and discipline to their lives. The retelling of these stories provided examples that Toughlove parents could survive and even conquer crises, kept members involved in the day-to-day life of the group, and preserved a sense of community among the members.

The Toughlove story promised a new beginning. The group's regular members described their desperation before they discovered Toughlove, and contrasted these feelings with the solace they felt once they embraced the Toughlove way of life. Although new members initially may have been reticent to tell their tales in the presence of strangers, their need to talk to someone was apparent as they blurted out their stories in a torrent of emotions.

In this drama, the parents left forever their roles as weak victimized players whose offspring tyrannized them and wreaked havoc on society. The Toughlove narrative empowered them to take charge of their families and demand the respect due them as elders. They would never again be failures, for only their children could lose in the Toughlove story. As one parent declared: "You have not failed - it is your children who are failing. Kids have to learn the consequences of their own actions." Still another added: "We made it easy for them, we covered the sharp edges so they would not bump into things when they learned to walk. We made it too easy-they never had to fight - we went to battle for them. Now they know how to push buttons and use us." Thus if their children were delinquent, they chose to be that way, and there are times when there is nothing that parents can do to modify their children's behavior. One group member asserted: "Sometimes you have to realize that your kid is a loser and that there isn't a damn thing that you can do about it." Group members nodded their assent.

\section{Thematic Analysis}

The narrative fiction created by this Toughlove group contained several key themes. First, individual tales were interwoven to explain the "good reasons" for abandoning the predominant rival story-the modern approach to child-rearing. In their drama, the old-fashioned values, characterized by strict discipline, were purported to be superior to today's methods of raising cildren. The group members often blamed "TLC" (tender loving care) for the problems they had with their children. One father observed: "While TLC works for some kids it is a bust with others." Another father chimed in, "The best way to raise kids is with discipline - strict discipline-that's how our parents did it and we sure didn't cause them these kinds of problems." Several group members claimed that they had tried to use the modern approach in 
raising their own children but that it had failed. These same parents expressed pride that they now had the courage to condemn these modern approaches. As one mother adamantly claimed: "Everything we are learning here in Toughlove is contrary to Dr. Spock." The other members readily agreed.

This call for a return to traditional values had fidelity because it resonated with stories from the parents' youth, and because the loss of the old ways accounted for the traumas they had experienced. In this sense, the Toughlove narrative was one of historical renewal, a promise that the past could be recreated and the security and comfort of a bygone era recaptured (Bass, 1983). Parents frequently told stories from their own childhood-about how it felt to "go to the woodshed." They commented that they had feared their own parents at times, but they also respected them. Their own children, they sadly agreed, neither feared nor respected them. As one mother noted: "We raised our kids like they did on TV and not the way we were raised. It always worked on TV. It sure didn't work in my house."

These parents believed they were good people who had been misled. The Toughlove narrative was appealing because it confirmed their self-perceptions and absolved them of their failures. They may have been too kind, too lenient, not tough enough, but it was their children who had really failed because they took advantage of their parents' kindness.

A second major theme of the Toughlove narrative was the parents' disdain for the child service professionals. The professionals became villains in the story for two primary reasons. First, the parents claimed these professionals were too quick to blame them for the failures of their offspring. Virtually all of the parents attending the meetings complained that they had been told by counselors, teachers, principals, and others that they were responsible for their children's behavioral problems. Second, these professionals were condemned as highly vocal proponents of the "modern" approaches to childrearing. Thus they were spokespersons for the dominant rival story-a story which, for the parents, lacked narrative coherence and fidelity, and a story which reflected an unrealistic approach to raising children. Accounts of visits to counselors were always a central part of an evening's storytelling. These "experts" were portrayed as naive - "book smart" but "experience dumb" and many group members related tales of their children "snowing" or "hoodwinking" the experts and bragging about it on their way home. Thus the professionals were depicted as part of the problem rather than as part of the solution.

Toughlove parents viewed the child care professionals' rival story as detrimental because it suggested that parents and children shared the responsibility for the problems in the home. The parents believed that this story gave their children an excuse to continue misbehaving. As adherents to the Toughlove narrative, the parents discounted the possibility that they were partially to blame for the problems in their homes. Several parents recalled that counselors had mentioned their drinking problems or martial difficulties as potential cuases for their children's misdeeds, but they claimed that it was "just a cop out" for kids to blame their parents for these problems. The 
Toughlove story, however, allowed parents to blame their children for their own problems, and doing so did not seem to make this story any less probable. On several occasions parents asserted: "This problem with my son is destroying my marriage." Or, "My daughter's behavior is causing me to drink too much."

In their role as experts on juvenile problems, supplanting the professionals, Toughlove parents placed most of the blame on their children and external factors. The enemies in the drama became the professionals, the media, the permissiveness of society, their children's friends, the lack of discipline in the schools, or modern approaches to child-rearing. If they as parents could be faulted at all, it was only that they had relied on the rival story and in so doing had become estranged from the "old-fashioned" values with which they had been raised.

The third central theme of the Toughlove narrative was that the system is pro-child, and that they could best cope with their problem children by depending on, and supporting, each other. The Toughlove group meeting was exalted as the one place were parents knew there would be people willing to listen to their problems without judging them. Group members consistently reported that the social service agencies, the schools, the police and the juvenile courts were of little help. The consensus of the group members was that "the laws protect kids, but it is parents who need protection."

The parents agreed that neither teachers nor police were helpful. The consistent story-line was that the schools did not teach, teachers could not control their students, and students were permitted to use drugs right on the school grounds. The police refused to come when they were called, and if they did come, they generally took the teenager's side in the dispute. One woman recalled that after her daughter was arrested for selling drugs the police picked her up to take her to a juvenile facility. On the way the officer was kind enough to stop by a friend's house so the girl could pick up her hairdryer.

The tales which recounted the utter helplessness these parents felt in coping with their past crises played an important part in the development of the group's shared story. If parents could not trust "the system" to resolve their problems, then they were all the more dependent on their fellow group members.

In this narrative fiction, the police and the juvenile system were both materially and symbolically anti-parent. The group members discussed how important it was to learn to protect themselves from the law. Several parents explained that their children had filed complaints against them, alleging child neglect or abuse, while their offspring were in fact destroying all harmony in the home and terrorizing their families. The group also discussed in great detail their responsibilities in providing for minor children. One woman insisted: "All parents are required by law to provide is a roof over their head and minimally sufficient clothing." Another mother told the group how she left home to escape from her son, leaving him only a loaf of bread and a jar of peanut butter to eat. The common thread running through most of these 
stories was the declaration that the police and the courts did not take these complaints seriously and failed to realize that these children represented a genuine threat to their parents and siblings. One angry mother related how the police told her that they could do nothing even though her son, whom she had thrown out, had returned to steal her possessions and destroy her furniture. The police refused to act because her house was still considered the boy's home, and, according to the officer, "A kid can't steal from himself, and can destroy his own house if he wants to."

Consistent with this theme, group members jointly developed language strategies to convince the police to arrest their children the next time they were called to the house. Several parents explained that the police would not take a teenager away the first, second, or even the third time they were summoned, but after that, if you labeled your child "incorrigible" you will have "hit upon the right legal mumbo-jumbo" to get him/her arrested. Other valuable information was given via stories-one mother explained that parents can report their kid missing after he leaves the house, "then after the police find him and bring him to the station you can refuse to pick him up, not accept custody. Then they have no choice, they have to put him somewhere else. That's what I did." She was upset because her son had been selling drugs in her house.

In contrast to the lack of help available from more conventional sources, the Toughlove narrative dramatized that if parents needed assistance they could always call upon another group member. As one of the group leaders recalled: "Crises don't happen between 8 AM and 5 PM when the social workers are willing to help. But if you are having trouble with your kid, even if it is midnight, you can call another Toughlove mom or dad. We will come by. These folks have come to my house when I needed help. And I've gone to theirs." Another member declared: "Kids have always had gangs. Now we have one too." Thus the Toughlove narrative encouraged parents to take heart - they had formed their own social services system, a support group that could circumvent or beat the system if necessary.

The fourth, and last, prominent theme in the narrative called for parents to put Toughlove into action by setting "bottom lines" for their children. These were the rules their children had to obey if they wanted to live with their family. The key to this strategy was that parents had to enforce their bottom lines, no matter what. The bottom lines set by individual parents were frequently discussed during the meetings. They included: you will not drink, you will not use drugs, you will attend school, you will meet this curfew, you will clean up after yourself, you will not entertain someone of the opposite sex in your bedroom, etc. By spelling out the behaviors appropriate for each of their children, and enforcing them, the Toughlove parents reinforced the shared group story that strict discipline was the answer to their troubles. Youths who did not meet their bottom lines were told they could no longer live at home. Although ejecting a son daughter from the house was to occur only as a last resort, several parents in this group had forced their children to leave home even though they had nowhere else to go. Two other parents 
managed to have their children detained ir. Juvenile Hall, a county detention facility, and one had commited her son to a private detoxification center. The group's leader said the message contained in these stories was a simple one: "Set rules for your kids. If they don't follow them, tell them, 'don't let the door hit you on your way out'." The Toughlove story thus chracterized even these very unhappy outcomes as positive developments. It was presumed better to be rid of these problem children than it was to have to endure the profound disruptions that they caused in the home.

Newcomers were warned that instituting the bottom lines was no easy task, as the group leaders and regulars related anecdotes regarding their children's initial difficulties when the new rules were set. One woman recalled that her daughter kept breaking the rules, so she refused to prepare her meals. Since her daughter could not even find the can opener in the kitchen, the mother found that she gained the girl's cooperation fairly quickly. One father told the group that his daughter's bottom line was to do well in school. To make up for lost time, she had to attend classes regularly, go straight home after school and not have visitors, do her homework, and also help keep the house clean. He discovered that all she did was talk on the phone all afternoon, so he removed the phones from his home every morning and locked them in the trunk of his car so that she could not contact her friends during the day. New Toughlove members quickly understoood that they were being prepared for a different type of battle than they were accustomed to, but one that they could hope to win.

During each meeting the group went through the reinforcing ritual of calling upon individual parents and asking them to describe what happened in their homes during the past week. Parents were asked to list the bottom lines they had set, and report whether or not their children had lived up to these rules. If a parent reported that one or more of the rules had been violated, the other group members cross-examined him/her to determine if the offending child had been suitably punished. Parents who showed signs of weakness were criticized, and parents who claimed they had been tough in enforcing the rules were praised by the other group members. This "grilling" of the parents allowed the Toughlove oldtimers to give encouragement to parents who were not used to standing firm. The Toughlove narrative left little room for "extenuating circumstances."

During this segment of storytelling, numerous parents exclaimed that their children were now behaving very differently as a result of the Toughlove program. Several expressed the conviction that they had finally managed to "win the respect" of their children-now that they could no longer be pushed around. These parents, furthermore, noted that while their children initially rebelled against the rules, they ultimately accepted them, because "children want and need discipline." The narrative was additionally strengthened when several parents commented that their children were happy that they had found Toughlove.

Most parents would leave the meeting after the story-telling/testimonial session, appearing more relaxed than when they arrived, imbued with the Toughlove spirit, and vowing to spread the word. Others, battered by recent 
crises, would remain to exchange sorrows, advice, hugs, and telephone numbers before braving the trip home.

\section{Implications of the Toughlove Story}

The Toughlove narrative proved to be comforting, engaging, predictable, and persuasive. Parents joined the group during times of cirsis, many feeling as if they had failed because they had been unable to instill socially appropriate values and attitudes in their children. Shamed by the reactions of friends, relatives, and child care experts, and resentful of a system that could not help and only blamed them for allowing such a disgraceful state of affairs to exist, they readily embraced the Toughlove narrative as an alternative for their problems.

Human communication works by identification, and these parents discovered that no one else understood life with delinquent children except other parents in similar circumstances. The rational world, with its scientific notions of child-psychology, and "Dr. Spock type experts," could not "speak" to them. The experts' story, which blamed them for their children's conduct, denied their own experiences and did not contain the formal or substantive features necessary for adherence. The Toughlove narrative met their needs and fulfilled the requirements for a good story, narrative probability - what constitutes a coherent story - and narrative fidelity - that a story rings true with a hearer's experience (Fisher, 1984). The story was probable because it was based on old-fashioned values, it restored the social order, and it placed blame where it belonged, on the shoulders of their disobedient and abusive offspring. The rival story which placed at least partial blame on the parents for their children's conduct was viewed as less probable. The story met the test of narrative fidelity because it resonated with their own feelings that they were essentially good people whose only failing had been that they were too permissive and not as tough as their own parents had been.

The Toughlove story was compelling because it so completely absolved parents of their guilt and relieved their sense of failure. The story also provided parents with a course of action that, at best, showed their children who was in charge and established rules they had to follow to remain part of the family, and at worst, allowed the remainder of the household to lead normal lives after the delinquent youth was "shown the door."

Despite the obvious appeal of these new "tough" approaches to childrearing, however, they are not without risk. The dimension of the Toughlove story which holds that children who do not adhere to their bottom lines should be ejected from the house is especially controversial. There is, of course, great danger that the ejected child may be unprepared to face life on his/her own and may in fact become a real threat to him/herself and to society. For instance, John Hinckley's parents were following the Toughlove philosophy when they insisted that their son become financially independent by March 20,1982, precisely the day that he shot President Reagan and three other men ("Hinckley's Family," 1984).

Hinckley's father has since embarked on a national speaking tour to warn 
parents of the dangers in the Toughlove approach declaring: "For heaven's sake don't kick somebody out of the house when they can't cope. But I'd never heard that before, and it (kicking John out of the house) seemed to me to make a lot of sense at the time" ("Hinckley's Family," 1984, p. 12). Hinckley's parents now urge other parents who are told to eject their children from home to be sure to seek the advice of those experts they had been told could not be trusted ("Hinckley's Family," 1984). This warning seems reasonable enough: parents should not take drastic steps when a more conservative means for disciplining children might work equally well - they should always proceed with caution.

Before this or any other rival story is likely to capture the trust and attention of the Toughlove parents, however, it needs to accomodate them as the hopeful, newly self-confident, bearers of old-fashioned values which they have become. If a rival story cannot capture people's self-conceptions, it does not matter whether or not it is "fact." Fisher noted that, "Any story, any form of rhetorical communication, not only says something about the world, it also implies an audience, persons who conceive of themselves in very specific ways" (Fisher, 1984, p. 14). Parents who do not have "problem children" may find the Toughlove story objectionable, but to those parents in the midst of a crisis the story has obvious appeal. The advocates of any rival story can win adherents only by "telling stories that do not negate the self-conceptions people hold of themselves" (Fisher, 1984, p. 14).

The other great danger in the Toughlove story is that it can be readily adapted to fit all children and all situations. For example, during our observation we noted that if parents told the group that they did not believe drugs or alcohol were responsible for their children's bizarre behavior, they were given a lecture on how to substantiate these abuses. Other potential reasons for their children's erratic or destructive behavior, including emotional or psychological disturbances, were dismissed without consideration. The Toughlove story thus proved quite elastic and was easily stretched to permit the conclusion that "bad drugs" or a "bad crowd" caused all behavior problems and, therefore, all required the same remedy.

The pressure to enact the Toughlove story was great; all parents had to play the "enforcer" role that ritualistically proved their faith, and imbued them with the credibility and unquestioned support granted only to other Toughlove moms and dads. While the group leaders seemed to be aware of the danger that parents might seek to get a quick-fix to their problems by ejecting their children from the house when far less drastic actions would be more appropriate, the potential danger from such decisions (as characterized by the Hinckley example) never appeared as imminent to the Toughlove parents as was the impending end to the chaos in their lives.

The truth or falsity of the Toughlove story is not really at issue in this study. What is important, is that through an analysis we can come to understand the appeal of stories and perhaps even learn how to avoid the creation of stories which might precipitate harmful consequences. Perhaps the most useful outcome of such study is that child care professionals and social service agencies can learn how to create better stories-stories which affirm parents' 


\section{REFERENCES}

Alibrandi, L.A. (1982). The Fellowship of Alcoholics Anonymous. In E.M. Pattison \& E. Kaufman (Eds.), Encyclopedic handbook of alcoholism (pp. 979-986). New York: Gardner Press.

Bartocci, B. (1984). My angry son: Sometimes love is not enough. New York: Donald I. Fine.

Bass, J.D. (1983). Becoming the past: The rationale of renewal and the annulment of history. In D. Zarefsky, M. Sillars \& J. Rhodes (Eds.), Argument in transition: Proceedings of the Third Summer Conference on Argumentation (pp. 305-318). Annandale, VA: Speech Communication Association.

Bodenhamer, G. (1984). Back in control: How to get your children to behave. Englewood Cliffs: Prentice-Hall.

Cowell, F.R. (1967). Cicero and the Roman Republic (4th ed.). Baltimore: Penguin Books.

David and Phyllis York treat problem teenagers with a stiff dose of "Toughlove." (1981, November 16). People, p. 101.

Emery, R.E. (1982). Intraparental conflict and the children of discord and divorce. Psychological Bulletin, 92, 310-330.

Fischer, D.G. (1983). Parental supervision and delinquency. Perceptual and Motor Skills, 56, 635-640.

Fisher, W.R. (1984). Narration as a human communication paradigm: The case of public moral argument. Communication Monographs, 51, 1-22.

Frentz, T.S. (1985). Rhetorial conversation, time, and moral action. Quarterly Journal of Speech, 71, 1-18.

Getting tough with teens. (1981, June 8). Time, p. 47.

Hinckley, J. \& Hinckley, J.A. (1985). Breaking Points. Grand Rapids, MI: Zondervan.

Hinckley's: Family on a crusade. (1984, February 23). Los Angeles Times, p. 12.

Knapp, M.S. (1979). Ethnographic contributions to evaluation research: The experimental schools program evaluation and some alternatives. In T.D. Cook \& C.S. Reichardt (Eds.), Qualitative and quantitative methods in evaluation research (pp. 118-139). Beverly Hills: Sage.

Landers, A. (1981, November). Giving kids "Tough" love. Family Circle, p. 34.

Loeber, R. \& Dishion, T. (1983). Early predictors of male delinquency: A review. Psychological Bulletin, 94, 68-99.

Morehouse, E. \& Richards, T. (1982). An examination of dysfunctional latency age children of alcoholic parents and problems in intervention. Journal of Children in Contemporary Society, 15, 21-33.

Nemy, E. (1982, April 26). For problem teen-agers: Love, Toughness. New York Times, p. B12.

Paperny, D.M. \& Deisher, R.W. (1983). Maltreatment of adolescents: The relationship to a predisposition toward violent behavior and delinquency. Adolescence, 18, 499-506.

Pattison, E.M. (1982). A systems approach to alcoholism treatment. In E.M. Pattison \& E. Kaufman (Eds), Encyclopedic handbook of alcoholism (pp. 1080-1108). New York: Gardner Press.

Pomerleau, O.F. (1982). Current behavioral theories in the treatment of alcoholism. In E.M. Pattison \& E. Kaufman (Eds.), Encyclopedic handbook of alcoholism (pp. 1054-1067). New York: Gardner Press.

Sanderson, J. (1983). How to raise your kids to stand on their own two feet. New York: Congdon \& Weed.

Stasiak, E.A. (1982). Nutritional approaches to altering criminal behavior. Corrective and Social Psychiatry and the Journal of Behavioral Technology, Methods and Therapy, 28, 110-115.

Wohl, L.C. (1985, May). The parent-training game-from "Toughlove" to perfect manners. Ms., p. 40.

York, P. \& York D. (1980). Toughlove. Sellersville, PA: Community Service Foundation. 
Copyright of Communication Quarterly is the property of Routledge, Ltd.. The copyright in an individual article may be maintained by the author in certain cases. Content may not be copied or emailed to multiple sites or posted to a listserv without the copyright holder's express written permission. However, users may print, download, or email articles for individual use. 